\title{
ОСОБЕННОСТИ ИСПОЛЬЗОВАНИЯ МЕТОДА ПРЕДМЕТНО-ЯЗЫКОВОГО ИНТЕГРИРОВАННОГО ОБУЧЕНИЯ (CLIL) С ЦЕЛЬЮ АКТИВАЦИИ ОБУЧЕНИЯ ИНОСТРАННОМУ ЯЗЫКУ СТУДЕНТОВ МАГИСТРАТУРЫ НЕЯЗЫКОВЫХ ВУЗОВ
}

\section{FEATURES OF USING THE METHOD OF CONTENT AND LANGUAGE INTEGRATED LEARNING (CLIL) IN ORDER TO ACTIVATE FOREIGN LANGUAGE TRAINING FOR GRADUATE STUDENTS OF NON-LINGUISTIC UNIVERSITIES}

S. Feopentova I. Lyamina T. Belyayeva

Summary: This article presents the results of a study aimed at establishing the specifics of using the content and language integrated learning (CLIL) method to activate foreign language teaching for master's students of nonlinguistic universities. In the context of the given topic, interdisciplinary issues of humanitarian knowledge related to professionally-oriented training and teaching professional disciplines through a foreign language are considered. Proposals on the construction of CLIL-maps and models of CLIL implementation of the method in the work of students of nonlinguistic areas of training on research projects, the structure, the content and a number of other accompanying educational process of the practical aspects of using the studied method are scientifically substantiated. Special attention is paid to the fact that CLIL occupies a specific niche in University practice, the formation of which is significant and becomes possible thanks to teachers who are equally proficient in their professional discipline and a foreign language. The results of the research allow us to draw a conclusion about the demand for content and language integrated training, which contributes to the creation of the most favorable conditions for the effective development of professionally significant information of disciplines of various cycles through a foreign language.

Keywords: subject-language integrated learning (CLIL) method, foreign language, undergraduates, professional education, CLIL-map, model, research projects.

\section{Введение}

олипарадигмальный характер современного педагогического процесса и необходимость организации вариативного образования обуславливают
Феопентова Светлана Владимировна

стариий преподаватель, Российский государственный аграрный университет-Московская сельскохозяйственная академия имени К.А. Тимирязева

sfeopentova@mail.ru

Лямина Ирина Мажитовна

старший преподаватель, Российский государственный аграрный университет-Московская сельскохозяйственная академия имени К.А. Тимирязева

lira2005@list.ru

Беляева Татьяна Константиновна преподаватель, Российский государственный аграрный университет-Московская сельскохозяйственная академия имени К.А. Тимирязева

tbelyayeva@mail.ru

Аннотация: В данной статье представлены результаты исследования, целью которого стало установление особенностей применения метода предметно-языкового интегрированного обучения (CLIL) для активации обучения иностранному языку студентов магистратуры неязыковых вузов. В контексте заданной темы рассмотрены актуальные междисциплинарные вопросы гуманитарного знания, взаимосвязанные с профессиональноориентированным обучением и преподаванием профессиональных дисциплин посредством иностранного языка. Научно обоснованы авторские предложения по построению CLIL-карты и модели реализации метода CLIL в работе магистрантов нелингвистических направлений подготовки над исследовательскими проектами, представлены структура, содержание и ряд других сопровождающих образовательный процесс аспектов практического использования изучаемого метода. Особое внимание акцентируется на том, что предметно-языковое интегрированное обучение занимает в вузовской практике конкретную нишу, формирование которой значимо и становится возможным благодаря преподавателям, одинаково владеющим своей профессиональной дисциплиной и иностранным языком. Результаты исследования позволяют сделать вывод о востребованности предметно-языкового интегрированного обучения, которое способствует созданию наиболее благоприятных условий для эффективного освоения профессионально значимой информации дисциплин различного цикла посредством иностранного языка.

Ключевые слова: метод предметно-языкового интегрированного обучения (CLIL), иностранный язык, студенты-магистранты, профессиональное образование, CLIL-карта, модель, исследовательские проекты.

необходимость перехода от отдельных альтернативных научных школ к системе интегративных инновационных технологий [2, с.91]. Впервые, практическая реализация педагогической интеграции была осуществлена в Великобритании в начале XX века в ходе разработки «коо- 
перированных курсов», позволивших совместить профессиональные знания с практической деятельностью. На сегодняшний день, интеграция в обучении изучена с точки зрения различных аспектов: общетеоретических, педагогических, научных знаний, практического синтеза и профессионального образования (В.С. Безрукова, Г.М. Добров, В.М. Максимова, О.М. Сичивица, И.А. Яковлев, С.М. Арефьева, С.Ю. Бурилова, В.В. Гузеев, В.А. Кленикова, В.М. Панфилова, В.Б. Синников, С.Ю. Страшнюк и др.). Под интеграцией следует понимать не суммирование знаний, представленных в различных научных предметах, а как инструмент преодоления противоречий, которые невозможно разрешить средствами одного предмета [3, с.28]. С точки зрения Л.И. Гриценко, «интегративный подход объединяет в себе интеграцию, представленную в виде принципа моделирования образовательной системы и процесса установления взаимосвязей между её компонентами» [1, с.73], представленными в виде содержания обучения, методики обучения и организации деятельности [1, с.74].

Интегративная природа иностранного языка и значимость иноязычной компетентности современных выпускников вуза в условиях интернационализации всех сторон жизнедеятельности человека диктуют необходимость модернизации методики его преподавания с целью овладения студентами инструментов расширения своих профессиональных возможностей и, соответственно, повышения конкурентоспособности. На сегодняшний день одной из подобных методик, в большей степени соответствующей требованиям современных реалий, является метод предметно-языкового интегрированного обучения, известный как CLIL (Content and Language Integrated Learning), позволяющий объединить в себе ряд подходов, широко используемых в различных образовательных контекстах. Концепция межпредметного языкового интегрирования была разработана двумя финскими учеными П. Мехисто и Д. Маршем [5, с.122]. Широкое распространение данного метода обусловлено тем, что он позволяет достигать одновременно две цели: первая цель - изучать содержание предмета с помощью иностранного языка (далее - ИЯ), и вторая цель совершенствование ИЯ в ходе педагогического процесca $[6$, c.38].

\section{Теоретическое обоснование проблемы исслелования}

Для достижения цели настоящего исследования, которая заключается в установлении особенности применения метода предметно-языкового интегрированного обучения (CLIL) для активачии обучения иностранному языку студентов магистратуры неязыковых вузов, первоначально, следует остановится на выявлении трудностей его реализации в сложившихся условиях образовательного процесса вуза.
Кроме дефицита методической литературы и программ обучения технологиям CLIL процесс реализации рассматриваемой нами методики осложняется рядом факторов, среди которых нами выделены следующие:

1. необходимость высокого уровня владения ИЯ преподавателем-предметником и определенным предметом для преподавания и того и другого, что осложнено недостаточностью багажа знаний;

2. необходимость владения ИЯ на оптимальном для освоения учебных предметов уровне самими обучающимися, несоответствие которого способно снизить качество образовательного процесса в целом;

3. соответствие сформированных в ряде случаев специфических профессиональных компетенций преподавателя, позволяющих ему реализовывать совершенно новый подход к проведению занятий и оценки приобретенных обучающимися знаний.

Для установления возможности реализации методики CLIL рассмотрим основные её компоненты, опираясь на представленные в ранее осуществленных исследованиях данные, в ходе теоретического анализа которых нами были выделены следующие, наиболее характерные: 1) content - содержание, стимулирующее процесс освоения знаний по конкретному предмету; 2) communication - общение, в ходе которого происходит практическое применение средств ИЯ с цель приобретения знаний по предмету; 3) cognition - мыслительные способности обучающегося для лучшего понимания языка и предмета; 4) culture - культурологические знания, как осознания особенностей альтернативных культур с целью понимания собственной [4, с.304].

Для достижения необходимого уровня развития лингвистических умений и предметных знаний, следует придерживаться четырехступенчатой схемы построения учебных занятий (4C):

- первая ступень - обработка текста, отвечающего требованиям визуализации информационного материала и структурой маркировки для наилучшего его понимания обучающимися;

- вторая ступень - организация приобретения знаний по предмету;

- третья ступень - языковое понимание текста, характеризующееся способностью воспроизвести содержание текста на ИЯ посредством использования простых и продвинутых языковых средств, специальной лексики текста и универсальных языковых единиц (устойчивых словосочетаний, фразовых глаголов и т.д.);

- четвертый уровень - учебные задания, соответствующие задачам обучения, уровню подготовки студентов, с учетом их предпочтений.

Опираясь на представленную организацию обучаю- 


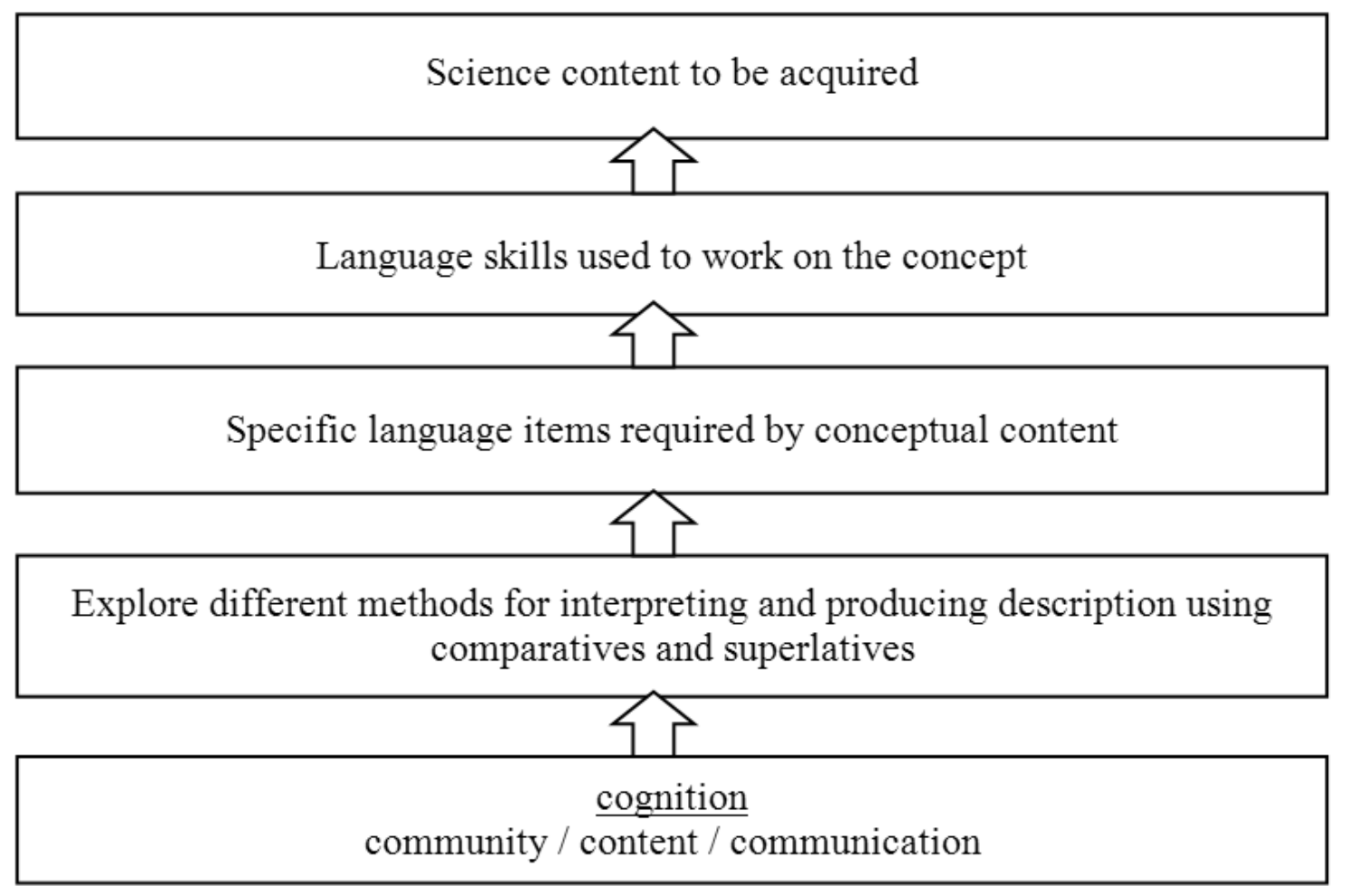

Рис. 1. CLIL-карта реализации работы над исследовательским проектом студентов нелингвистических направлений подготовки

щего процесса при использовании методики CLIL, перед преподавателем ставятся ряд задач, требующих разрешений, в частности:

1. применяемый в ходе обучения материл по предмету должен соответствовать уровню сложности немного ниже актуального уровня знаний обучающихся на родном для них языке, а предоставляемые им тексты сопровождены оптимальным количеством заданий, достаточным для освоения представленной учебной информации;

2. используемые учебные задания должны быть выстроенные с акцентированием внимания на предметном содержании;

3. включённые учебные задания должны достаточно ярко демонстрировать специфические особенности лингвистических форм, позволять вырабатывать умение в их создании и употреблении;

4. учебные задания, применяемые в ходе организации образовательного процесса, должны быть ориентированы на активизацию самостоятельной и творческой деятельности студентов и носить преимущественно коммуникативный характер.

В настоящее время в практике использования CLIL концепции в условиях образовательного пространства вуза широкое распространение получили три модели:

- первая модель ориентирована на расширение языкового образования путем проведения 1-2 часовых занятий в неделю (weak form), используя учебный материал по отдельным темам предмета или нескольких предметов;

- вторая модель структурно организована в виде модульного преподавания, и, в свою очередь, реализуется на разных этапах образовательного процесса в виде освоения конкретного модуля, направленного на изучение одного или нескольких предметов на ИЯ;

- третья модель характеризуется частичным слиянием с предметом и реализуется путем проведения до 50\% учебных занятий по ИЯ в формате методики CLIL.

\section{Результаты исследования}

В качестве одной из наиболее ярких отличительных особенностей построения CLIL-обучения выступает то, что исходной точкой в концепции «4С» является профессиональный контент, т.е. предметное содержание, в связи с чем визуализируем сказанное на конкретном примере - варианте CLIL-модели реализации исследовательского проекта студентами (см. рисунок 1).

Представленные составляющие модели CLIL позволяют в ходе работы над исследовательским проектом регулировать билингвальные процессы познания (мышления), которое выступает в качестве ментальной способности познания (содержания), а в виду того, что смыслотворчество, заключенное в исследовательской 


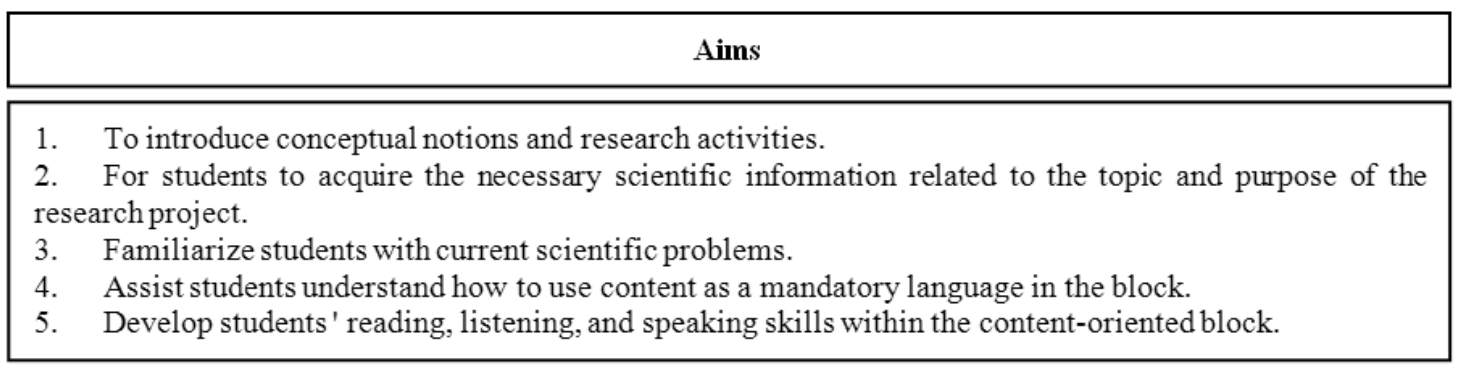

\section{Criteria for assessment}

1. Assess student understanding of the concept of research design;

2. Assessment literacy build fundamental stages of the design and research activities in general;

3. The correct choice of the main methods in the implementation of the study;

4. Providing a presentation of the major achievements of the research project; the amount of personal contribution of the student in developing the research project.

\section{Teaching objectives (What I plan to teach)}

\begin{tabular}{|c|c|}
\hline $\begin{array}{l}\text { Content } \\
\text { 1. Content in the context of } \\
\text { the research project topic. } \\
\text { 2. Main definitions. } \\
\text { 3. Characteristics of scientific } \\
\text { activity. } \\
\text { 4. Static methods of } \\
\text { processing quantitative and } \\
\text { qualitative values of the main } \\
\text { indicators. }\end{array}$ & $\begin{array}{l}\text { Cognition } \\
\text { 1. Instill confidence in students. Provide students with the } \\
\text { opportunity to understand the key features of research design. } \\
\text { 2. Enable students to apply new knowledge in research and design } \\
\text { activities. } \\
\text { 3. Encourage the transfer of new knowledge into active use. } \\
\text { 4. Enable students to learn how to use content - required language } \\
\text { within the block. } \\
\text { 5. Provide students with opportunities for creative use of content as } \\
\text { mandatory and spontaneous language use in a cooperative group }\end{array}$ \\
\hline
\end{tabular}

\section{Culture}

1. Research and define the concept of research activities in Russia.

2. Understand the importance of the specifics of socio-economic realities in country

Communication
Language of learning - Language for learning - Language through learning

By the end students will be able to:

\section{Learning outcomes}

1) demonstrate the concept and its related features;

2) engage in visual matching between concepts and images;

3) interpret visual information;

4) use language creatively;

5) use a class vocabulary record of new words.

Рис. 2. Модель реализации метода CLIL в работе студентов нелингвистических направлений подготовки над исследовательским проектом

деятельности, можно представить как личностный, так и социальный процесс (сообщество), новые знания и навыки развиваются через личностную, через кооперативную рефлексию / анализ (познание) и через коммуникативный процесс (коммуникация).

B качестве преимущества применения CLIL в работе над исследовательским проектом студентов нелингвистических направлений подготовки, следует отметить:
1. интегрированность знаний, которые способствуют повышению мотивации студентов к изучению ия в виду необходимости его использования в качестве средства освоения научной информации в ходе работы над исследовательским проектом: желание понять и использовать содержание мотивирует к изучению языка;

2. расширение возможностей говорить и писать о 
наблюдаемых и анализируемых в процессе работы над исследовательским проектом процессах;

3. непосредственное применение полученных в ходе работы над исследовательским проектом знаний и умений с целью получения конечного запланированного результата;

4. применение ИЯ как мощного инструмента расширения профессиональных знаний и умений;

5. расширение кругозора студентов и их приобщение к культурным ценностям;

6. получение реального опыта, оказывающего значимое влияние на индивидуально обусловленные способности как к предмету познания, так и к изучению ИЯ (см. рисунок 2).

\section{Выводы исследования}

Подытоживая полученные в ходе исследования результаты, следует отметить, что представленные в работе авторские CLIL-карта и модель реализации метода CLIL в работе студентов нелингвистических направлений подготовки над исследовательскими проектами позволяют выстроить предметно-языковое пространство интегрированного обучения, активизируя освоение ИЯ студентами магистратуры неязыковых вузов, что несомненно имеет практическую значимость в сложившихся современных условиях и в контексте требований, предъявляемых к выпускнику вуза.

\section{ЛИТЕРАТУРА}

1. Гриценко, Л.И. Основы интегративного обучения [Текст] / Л.И. Гриценко // Образование и наука. - 2009. - №5 (62). - С.73-74.

2. Салехова, Л.Л. и др. Content and Language Integrated Learning как основа формирования профессиональной иноязычной компетенции студентов технических вузов [Текст] / Л.Л. Салехова, К.С. Григорьева // Иностранный язык для профессиональных целей: традиции и инновации: Сб. ст. ІІ заочный республиканский симпозиум - Казань: К(П)ФУ, 2013. - С. 89-94.

3. Сериков, Г.Н. Социально-значимые аспекты самоопределения личности [Текст] / Г.Н. Сериков // Вестник ЮУрГУ. Серия «0бразование. Педагогические науки». - 2014. - Т.6. - № 4. - С. 27-32.

4. Coyle D. CLIL: towards a connected research agenda for CLIL pedagogies / D. Coyle // International Journal of Bilingual Education and Bilingualism. - 2007. Vol.10. - №5. - P.302-305.

5. Coyle, D. CLIL: Content and Language Integrated Learning / D. Coyle, Ph. Hood, D. March. - Cambridge: Cambridge University Press, 2010. - P.122.

6. Mehisto P. Uncovering CLIL: Content and Language Integrated Learning in Bilingual and Multilingual Education / P. Mehisto, D. Marsh, M.J. Frigols. - L.: Macmillan, 2008. - P. 38 .

( Феопентова Светлана Владимировна (sfeopentova@mail.ru), Лямина Ирина Мажитовна (lira2005@list.ru), Беляева Татьяна Константиновна (tbelyayeva@mail.ru).

Журнал «Современная наука: актуальные проблемы теории и практики» 